\title{
MAQUIAVEL E A FUNÇÃO DOS TUMULTOS PARA A POTÊNCIA MILITAR ROMANA ${ }^{1}$
}

\author{
Douglas Antônio Fedel Zorzo 2 \\ Universidade do Estado do Paraná (UNIOESTE) \\ https://orcid.org/0000-0002-3768-4253 \\ E-mail: douglasfedel@hotmail.com
}

\section{RESUMO:}

O artigo apresenta uma investigação, no âmago do pensamento de Nicolau Maquiavel, sobre o papel que os conflitos romanos ocorridos entre nobres e plebe tiveram para que a República de Roma se tornasse uma potência militar. $\mathrm{O}$ entrechoque de desejos de grandes e povo foi responsável por promover naquela cidade um autêntico vivere civile e libero, mas também foi a principal causa de sua expansão político-militar. Aqui, buscaremos elucidar os motivos que alçaram Roma àquela grandeza. Em um primeiro lugar, as dissensões ocasionaram o aperfeiçoamento constitucional das instituições romanas, encaminhando-as rumo a um estado republicano de governo misto. Com a instituição dos Tribunos da Plebe, o povo alcançava seu reconhecimento político, possibilitando que os exércitos fossem formados pelos próprios cidadãos advindos da plebe. Em segundo lugar, a regulação institucional dos conflitos e o anseio expansionista de Roma foram a razão pela qual a "guarda da liberdade" havia sido confiada à plebe, promovendo um governo popular, medida que permitiu que a República se voltasse para campanhas expansionistas em direção a conquista do império. Em terceiro lugar, reconhecer o conflito e institucionalizá-lo foi um meio para precaver-se dos caprichos da fortuna. Dessa forma, regular institucionalmente os eventos que atribulam a ordem política interna significava dar garantias para que os confrontos externos fossem bem-sucedidos.

PALAVRAS-CHAVE: Maquiavel; Conflito; Potência militar.

\section{MACHIAVELLI AND THE ROLE OF TUMULTS FOR THE ROMAN MILITARY POWER}

\begin{abstract}
:
The paper presents an investigation, at the heart of the thought of Niccolò Machiavelli, about the role played by Roman conflicts between nobles and plebs in order for the Republic of Rome became a military power. The clash of desires of great and people was responsible for promoting in that city an authentic vivere civile and libero, but also was the driving force of its military-political expansion. Here, we will intend to elucidate the reasons that have elevated Rome to that greatness. First, the dissensions caused the constitutional improvement of Roman institutions, directing them towards a republican state of mixed government. With the institution of the Tribunes of Plebeians, the people reached its political recognition, which created the possibility for the armies to be formed by the citizens from the plebs. Secondly, the institutional regulation of the conflicts and the expansionist impetus of Rome were the reason why the "guard of liberty" had been entrust to the plebs, promoting a popular government, a measure that allowed the Republic to turn to expansionist campaigns towards the conquest of the empire. Thirdly, recognizing the conflict and institutionalizing it was a mechanism to protect themselves from the caprices of fortune. Therefore, the institutional regulation of the events that afflict the internal political order meant to give guarantees for that those external confrontations could be successful.
\end{abstract}

KEYWORDS: Machiavelli; Conflict; Military power.

1 O presente trabalho é resultado da pesquisa de mestrado e foi realizado com apoio da Coordenação de Aperfeiçoamento de Pessoal de Nível Superior (CAPES), Brasil, Código de Financiamento 001.

2 Doutorando em Filosofia na Universidade do Estado do Paraná (UNIOESTE), Toledo - PR, Brasil.

ZORZO, Douglas Antônio Fedel. Maquiavel e a função dos tumultos para a potência militar romana. Griot : Revista de Filosofia, Amargosa - BA, v.19, n.2, p.284-299, junho, 2019. 


\section{Introdução}

O capítulo 4 do Livro I dos Discursos sobre a primeira década de Tito Lívio, de Nicolau Maquiavel, porta, em seu enunciado, uma das teses mais engenhosas desta obra: a desunião entre a plebe e o senado tornou livre e poderosa a república romana. Liberdade e potência, duas dimensões essenciais para que a reputação da cidade fosse fixada na história como paradigma do regime republicano.

Porém, se a grandeza de Roma não era passível de contestação, a causa dessa excelência ainda estava em aberto. Ao afirmar que foram os tumultos entre a plebe e a nobreza a causa de a República ter se tornado uma cidade libera e potente, o Secretário florentino operava um delicado movimento de subversão a toda uma linha de pensamento político, suspendendo a concepção ciceroniana de concordia ordinum, que, ao contrário, depositava na harmonia interna e no consenso a possibilidade de florescimento das instituições livres ${ }^{3}$.

Nesse sentido, devemos notar que a "liberdade" e a "potência", enraizadas nos conflitos entre os grandes e o povo, tornaram-se o objeto de diversos estudos maquiavelianos - em especial daqueles que se debruçam sobre as nuances de seu republicanismo. Todavia, entre os termos, é o problema da liberdade que tem despertado maior atenção dessa literatura crítica ${ }^{4}$ Por certo, o acalorado debate que se constrói em torno dessa temática não é gratuito. Como Maquiavel sustentaria, no seio da comunidade política, essa liberdade aparece como uma condição indispensável à potência militar. Mas, a mesma liberdade, nascida da incompatibilidade dos humores do corpo político, apenas pode ser preservada se a autonomia política da cidade, através dos instrumentos militares, também for assegurada.

A libertà e a potenza são, assim, complementares. Dessa forma, no presente artigo nos propomos a investigar, pontualmente, como os conflitos romanos, os tumultos entre a nobreza e a plebe, foram responsáveis pelo poder militar daquela República, considerando as reformas institucionais também por eles causadas, que possibilitaram a conquista do mundo e a posterior - e paradoxal - formação do Império ${ }^{5}$.

\footnotetext{
3 A condenação desses conflitos, como nos recorda Newton Bignotto (2005, p. 84-85), era um dos raros pontos em torno do qual "todos os florentinos tinham a mesma opinião. De Dante aos humanistas, todos se apressavam em demonstrar seu papel negativo na vida política da cidade". Nessa mesma direção, para Gennaro Sasso (2014, p. 438, tradução nossa), uma "antiga tradição de pensamento" havia identificado nessa noção "a felicidade das repúblicas". Maquiavel estaria "plenamente consciente dessa tradição": sabia "que era a opinião da maioria" e que ela havia passado "dos antigos aos modernos". O capítulo 4, por isso "revolucionário", coloca como o "fundamento do estado bem ordenado" não a "concórdia", concebida estaticamente, mas "a discórdia, o conflito, o confronto dos "humores" contrapostos que sempre se encontram para conflituar [confliggere] no profundo coração das repúblicas".

${ }^{4}$ Cf., por exemplo, GAILLE-NIKODIMOV, Marie. Conflit civil et liberté: La politique machiavélienne entre histoire et médiecine. Paris: Honoré Champion, 2004. NADEAU, Christian. Machiavel: domination et liberté politique. Philosophiques, v. 30, n.2, p. 321-351, 2003. PETTIT, Philip. Republicanism: a theory of freedom and government. Oxford: Oxford University Press, 1997. AUDIER, Serge. Machiavel, conflit et liberté. Paris: Vrin/Ehess, 2005. Em língua portuguesa, cf. ADVERSE, Helton. Maquiavel, a república e o desejo de liberdade. Trans/Form/Ação, v. 30, p. 33-52, 2007; AMES, José Luiz. Liberdade e conflito: o confronto dos desejos como fundamento da ideia de liberdade em Maquiavel. Kriterion, ${ }^{\circ} 119$, p. 179-196, 2009.

5 Sobre este paradoxo cf. SASSO, Gennaro. Niccolò Machiavelli: storia del suo pensiero politico. Bologna: Il Mulino, 1980, p. 485-502.
} 


\section{Os tumultos e o aperfeiçoamento institucional romano: a primeira condição para a potência}

Antes de tudo, devemos notar que a virtude militar romana era um dado histórico incontestável, admirada, até mesmo, por aqueles que atribuíam às suas ordenações um estado tumultuário, conturbado e repleto de confusões. Essa chave de avaliação historiográfica, difundida por "muitos" - dentre eles Plutarco e o próprio Lívio $^{6}$, mas também pelos contemporâneos, como Francesco Guicciardini ${ }^{7}$-, identificava na capacidade militar, somada a uma boa fortuna, a razão pela qual aquela caótica república havia sido capaz de manter-se por tanto tempo. Pois, afirmavam, caso faltasse a virtude das armas, "ela teria sido inferior a qualquer outra república" (Discursos, I, 4, p.21).

Contrário a essa opinião, Maquiavel argumenta que aqueles que assim avaliavam a cidade de Roma haviam deixado de compreender que "em toda república há dois humores diferentes [umori diversi], o do povo e o dos grandes, e que todas as leis que se fazem em favor da liberdade nascem da desunião deles" (Discursos, I, 4, p. 22). Nesse sentido, "direi [io dico] que quem condena os tumultos entre os nobres e a plebe parece censurar as coisas que foram a causa primeira da liberdade de Roma", considerando mais "as assuadas e a grita que de tais tumultos nasciam do que os bons efeitos que eles geravam" (Discursos, I, 4, p. 21-22, grifos nossos). Ora, contesta o Secretário florentino, não se pode ter "razão para chamar de não ordenada uma República dessas, onde há tantos exemplos de virtù", uma vez que, por decorrência lógica, "os bons exemplos nascem da boa educação; a boa educação, das boas leis; e as boas leis, dos tumultos que muitos condenam sem ponderar" (Discursos, I, 4, p. 22).

\footnotetext{
6 "Foi opinião de muitos - e, entre estes, Plutarco, seriíssimo escritor - que o povo romano, na conquista do império, foi mais favorecido pela fortuna que pela virtù. [...] E parece que essa mesma opinião foi abraçada por Lívio, porque são raras as vezes em que, citando algum romano que fale da virtù, não lhe acrescente a fortuna. Opinião que não pretendo professar de modo algum, e não creio tampouco que possa ser defendida" (Discursos, II, 1, p. 181).

7 É justamente a tese que emana das colocações de Bernardo del Nero, uma das principais vozes do Dialogo del reggimento di Firenze. De acordo com o interlocutor, "nem me alegueis os romanos, juntos aos quais, em um viver popular e tumultuário [tumultuoso], floresceu tanto a disciplina militar", pois, justifica, essa disciplina "nasceu e cresceu sob o rei", isto é, durante o período monárquico, e "quando a cidade se liberou, não foi difícil nem novo continuar naquela arte na qual [a cidade] já era nutrida por centenas de anos e que é possível dizer, então, que era um exercício comum" (GUICCIARDINI, 1974, p. 392, tradução nossa). Depois, o moderador do diálogo, Piero Guicciardini, parece remeter diretamente ao pensamento maquiaveliano: "vós tendes louvado as armas dos romanos como merecidamente são louvadas por todos, e condenado [biasimato] muito o governo interno, o que também é a opinião de muitos". Porém, "eu ouvi alguém afirmar o contrário, e as razões que eles alegam são que, diante daquele fundamento que ninguém nega, nem pode negar, de que sua milícia era boa, é necessário confessar que a cidade tinha boas ordenações, pois, ao contrário, não teria sido possível a boa disciplina militar". Por consequência, os tumultos entre os grandes [padri] e a plebe, "entre os cônsules e os tribunos, eram mais assustadores na demonstração do que no efeito, e aquela confusão que nascia deles não desordenava as coisas substanciais da república". Assim, como o "número do senado" era pequeno, e "aquele do povo grandíssimo, era necessário que os romanos se dispusessem ou a não se servir do povo nas guerras, o que teria eliminado a ocasião de fazer aquele grande império, ou querendo poder manejá-lo, os suportassem e deixassem que desafogassem seus humores [sfogare gli umori], que não tendiam a outra coisa senão à defesa da opressão dos mais poderosos" (GUICCIARDINI, 1974, p. 449-450). Apesar da objeção, Bernardo permanece firme em seu posicionamento: "digo [...] que o governo interno [de Roma] foi tumultuoso e cheio de sedições [pieno di sedizione], que se não tivesse havido a vigorosa virtù militar teriam muitas vezes precipitado aquela república. $\mathrm{E}$ isso, ao meu juízo, procedia de ser mal ordenada" (GUICCIARDINI, 1974, p. 451).
}

ZORZO, Douglas Antônio Fedel. Maquiavel e a função dos tumultos para a potência militar romana. Griot : Revista de Filosofia, Amargosa - BA, v.19, n.2, p.284-299, junho, 2019. 
Então, estamos diante de "dois humores diversos", que marcam presença em "todas as cidades"8. Toda organização política é atravessada por esta divisão que separa os indivíduos em dois grupos diametralmente distintos: de um lado, os grandes, que desejam "comandar e oprimir o povo"; de outro, o povo, que "não quer ser comandado nem oprimido pelos grandes" (O Príncipe, IX, p. 43) $)^{9}$.

A caracterização de cada umore, observa Marco Geuna $(2005$, p. 24, tradução nossa), se deve aos modos possíveis de entender e fazer experiência da liberdade. Aos grandes, a associação em torno desse grupo corresponde ao fato de que ser livre é comandar e oprimir; ao povo, a união se deve à expressão de seu desejo de liberdade, antagônica àqueloutra: não ser comandado nem tampouco oprimido. Nesse contexto, resume José L. Ames (2009, p. 185), o conflito se instaura porque a maneira como grandes e povo quer ser livre é diversa ${ }^{10}$. Isto é, a contraposição irrompe uma vez que a maneira como cada parte tenta efetivar seu desejo contrapõese com a maneira com que a outra categoria tenta consumar o seu.

Em Roma, a diversidade antagônica do desejo de liberdade dessas duas categorias havia ocasionado uma sucessão de tumultos que, se, por um lado, ameaçava a integridade política da República, ao menos aos olhos de uma série de leitores, por outro, agora, deveriam ser considerados enquanto a fonte de um autêntico vivere libero e civile, responsável por alçá-la à grandeza. Humores diversos, grandes e povo, nobres e plebe, ou, no nível institucional, Senado e Tribunos: eis os atores dos conflitos aos quais Maquiavel atribuía o protagonismo para a potência romana.

A primeira manifestação dessa oposição como condição para a grandeza romana é de natureza preambular. As dissensões entre a plebe e a nobreza foram responsáveis pelo aperfeiçoamento institucional de Roma, isto é, pela reestruturação da república em direção a um governo misto de inclinação popular - o que irá operar como base para a formação de sua imponente estrutura militar. Com efeito, os tumulti foram a razão de a cidade ter se tornado uma republica più perfetta.

No capítulo 2 do Livro I, Maquiavel contextualiza esse movimento nos seguintes termos: quando olhamos para a ordenação constitutiva de um estado, devemos levar em consideração que enquanto algumas cidades "receberam leis, em seu princípio ou depois de não muito tempo, de um só homem e de uma só vez", como Licurgo havia feito com Esparta, outras "as receberam ao acaso [a caso] e em várias vezes, segundo os acontecimentos [li accidenti] - como ocorreu com Roma" (Discursos, I, 2, p. 12-13).

\footnotetext{
8 "Quem espera que uma república possa ser unida muito se ilude com tal esperança” (História de Florença, VII, 1, p. 422), pois "[...] são sempre os mesmos desejos e os humores em todas as cidades e em todos os povos [tutti $i$ popoli] [...] e eles sempre existiram" (Discursos, I, 39, p.121). Sobre a dimensão "natural" da divisão, cf. também História de Florença, II, 12, p.94-95; III, 1, p. 157.

9 Como sustentará Geuna (2005, p. 23, grifos nossos), essa cisão do corpo político é, portanto, original e constitutiva. Ou seja, Maquiavel parte de uma pluralidade do corpo político e social. Gérald Sfez (1999, p. 172), por seu turno, destaca que, então, para Maquiavel a vida política era fundada sobre um acordo qui jure: um acordo que visa submeter o desacordo.

10 Cf. SFEZ, Gérald. Machiavel, la politique du moindre mal. Paris: Presses Universitaires de France, 1999. Particularmente o capítulo 3, "Le différend des humeurs", p.172-215.
} 
Recuperando uma argumentação de matriz polibiana ${ }^{11}$, a perfezione de um estado remetia à sua organização em conformidade com um regime misto de governo. Em síntese, a premissa maquiaveliana postulava seis formas políticas imputáveis a uma cidade. Por um lado, três "boas em si mesmas": o principado, o governo optimata e o popular. Por outro, três "péssimas", que operam como uma degeneração das formas "boas": a tirania, decorrente do principado; o "governo de poucos", como uma deterioração dos optimates; e a licença, como decadência do popular (Discursos, I, 2, p. 14).

Porém, a "brevidade da vida que há nos três bons", isto é, sua fácil passagem para o formato corrompido, e a "malignidade que há nos três ruins", torna todos esses modos, singularmente considerados, "nocivos". É por isso que "aqueles que prudentemente ordenaram leis", sempre que "tiveram conhecimento desse defeito", evitaram "cada um desses modos por si mesmos", optando por um que tivesse "um pouco de todos, por o julgarem mais firme e estável", visto que "quando numa mesma cidade há um principado, optimates e governo popular, um toma conta do outro" (Discursos, I, 2, p. 17).

Assim, enquanto Esparta, desde o momento de sua fundação, desfrutava dessa condição, por obra imediata de Licurgo, que havia dado "aos reis, aos optimates e ao povo suas devidas partes", possibilitando que sua obra durasse mais de "oitocentos anos, com supremo louvor para si e sossego para aquela cidade" (Discursos, I, 2, p. 17), Roma a alcançaria através de vias oblíquas. Ainda que Rômulo, seu suposto ordenador inaugural, e todos os outros reis que a ele se se seguiram, tenham feito "muitas e boas leis", em "conformidade com a vida livre", sua "finalidade [fine] foi fundar um reino e não uma república", de modo que "quando aquela cidade se tornou livre, faltavam-lhe muitas coisas que cumpria ordenar em favor da liberdade" (Discursos, I, 2, p. 18).

Com a deposição da monarquia e a expulsão do último rei, os romanos imediatamente ordenaram "dois cônsules" para ocuparem o lugar do "poder régio". Ali, o Consulado somava-se ao Senado" ${ }^{12}$, já ativo, de modo que "aquela república vinha a ser mescla de duas qualidades das três acima citadas, ou seja, principado e optimates". Faltava apenas "dar lugar ao governo popular" (Discursos, I, 2, p. 19). Nesse sentido, embora lhes faltasse um Licurgo, "foram tantos os acontecimentos que nela surgiram, devido à desunião que havia entre a plebe e o Senado, que aquilo que não fora feito por um ordenador foi feito pelo acaso" (Discursos, I, 2, p. 18).

A disunione, em questão, foi responsável pelo aperfeiçoamento das ordenações romanas por meio da criação dos Tribunos da Plebe, uma instância política voltada à parcela popular dentro da estrutura institucional romana ${ }^{13}$. Como relata Maquiavel no capítulo 3 , a presença da monarquia dos Tarquínios intimidava a nobreza da cidade, que, por esse motivo, se continha para não abusar da plebe, tratando-a humanamente, temendo que ela se aproximasse daqueles reis. Todavia, após a

\footnotetext{
${ }^{11}$ Sobre isso, Cf. POLIBIO, Le storie. Trad. de Carla Schick. Vol. II. Milano: Arnoldo Mondadori Editore, 1955, Livro VI, 3-11, p. 92-100.

12 Como observa Inglese (2015, p. 200, nota 33), os cônsules eram Lúcio Júnio Bruto e Lúcio Tarquínio Colatino. O Senado, por sua vez, havia sido criado por Rômulo, de modo que "a primeira e parcial mikté entre monarquia e aristocracia remonta às origens da própria história romana".

${ }^{13}$ Novamente de acordo com Inglese (2015, p. 202-203, nota 9), o Tribunato, instituído em 494 a.C, tinha o poder de vetar ou cassar atos e decretos lesivos à plebe.
}

ZORZO, Douglas Antônio Fedel. Maquiavel e a função dos tumultos para a potência militar romana. Griot : Revista de Filosofia, Amargosa - BA, v.19, n.2, p.284-299, junho, 2019. 
destituição do regime, os grandes "começaram a cuspir sobre a plebe o veneno que haviam guardado no peito, ofendendo-a de todos os modos que podiam" (Discursos, I, 3, p. 20). Disso, após "muitas confusões, tumultos e perigos de perturbações", "chegou-se à criação dos Tribunos, para a segurança da plebe" (Discursos, I, 3, p. $21)^{14}$. Com tal medida, Roma encarnava o verdadeiro governo misto, com os Cônsules representando o principado, o Senado, os optimates, e os Tribunos da Plebe o governo popular.

A nova instância não significava apenas o estabelecimento formal de uma esfera até então faltosa para o governo misto. Mas, sobretudo, instituía a plebe enquanto sujeito político, obrigando que os grandes reconhecessem seus anseios através dos canais institucionais. Essa reforma foi imprescindível para que os exércitos romanos, peça central à potência, daí em diante, fossem formados e engrossados pelos próprios cidadãos advindos da plebe. A condição para o povo ir à guerra era que o estado outorgasse legitimidade àqueles conflitos, regulando-os através de ordini e leggi. Incluir o povo no centro do jogo político representava, com efeito, o primeiro passo a ser dado para a posterior conquista do mundo.

Por essa razão, a criação dos Tribunos tornou-se a condição primeira da sucessiva potência e grandeza da república, isto é, a premissa do império. Pois, o povo que constituía o "nervo" daqueles exércitos e arriscava a vida nos campos de batalha, como propõe Sasso (1980, p. 462, tradução nossa), sabia que "tão alto, aquele risco devia bem ser corrido em defesa de uma pátria, que não era a propriedade dos patrícios, mas a casa de todos os romanos".

Nesse sentido, sugere Maquiavel, "digo que toda cidade deve ter os seus modos para permitir que o povo desafogue sua ambição [sfogare l'ambizione sua], sobretudo as cidades que queiram valer-se do povo nas coisas importantes" (Discursos, I, 4, p. 22), como na guerra. A criação de mecanismos institucionais para dar sfogo às expressões da categoria popular é necessária: os tumultos não podem ser sufocados para evitar os inconvenientes por eles causados, sem que, com isso, se origine um corpo político frágil, desarmado, presa fácil para as demais potências.

Em Roma, por exemplo, quando o povo desejava obter uma lei, fazia florescer os tumultos, onde era possível ver o povo "gritar contra o senado, o senado contra o povo, a correr em tumulto pelas ruas, a fechar o comércio, a sair toda a plebe de Roma" (Discursos, I, 4, p. 22); ou simplesmente "se negava a arrolar seu nome para ir à guerra, de tal modo que, para aplacá-lo, era preciso satisfazê-lo em alguma coisa" (Discursos, I, 4, p. 23).

Como aponta John McCormick (2001, p. 300, tradução nossa), esse modus operandi estava presente nos eventos que precederam a criação do Tribunato. A plebe, abandonando Roma em massa, foi chamada de volta pela nobreza, que temia "pela defesa da cidade", decorrendo, disso, a instituição daquele poder popular ${ }^{15}$. Notemos: na base dessa instituição encontrava-se a preocupação pela segurança

14 “[...] tornando-se a nobreza insolente [...] o povo sublevou-se contra ela; e assim, par anão perder tudo, ela foi obrigada a conceder ao povo a sua parte, e, por outro lado, o Senado e os Cônsules ficaram com tanta autoridade que puderam manter suas respectivas posições" (Discursos, I, 2, p. 19).

${ }^{15}$ Lívio (Livro II, capítulo 32) confirma que a plebe, sob a autoridade Sicinus, recusou-se a ir para a guerra contra os équos, retirando-se ao Monte Sacro. Para reverter a situação, exigiam que a eles fossem concedidos magistrados próprios, os Tribunos. Sobre isso, cf. LIVIO, Tito. Storie: Libri I-V. A cura di Luciano Perelli. Torino: UTET, 1974, p. 353.

ZORZO, Douglas Antônio Fedel. Maquiavel e a função dos tumultos para a potência militar romana. Griot : Revista de Filosofia, Amargosa - BA, v.19, n.2, p.284-299, junho, 2019. 
militarizada da cidade. Um posicionamento similar é apresentado por Marie GailleNikodimov (2004, p. 56, tradução nossa), que sustenta que na história romana a formulação de leis em troca da participação na guerra "aparecem como acontecimentos inelutáveis" 16 . A longa duração da cidade e de seu império "impuseram adequações constitucionais".

Essas primeiras modificações, portanto, estão diretamente relacionadas com a questão dos exércitos romanos. O reconhecimento das dissensões e o controle dos conflitos pelas vias institucionais significava que a república havia tocado em um autêntico vivere libero, e, exatamente por isso, que as campanhas de expansão territorial encontravam resultados positivos. A liberdade, no final, entendida não somente como a impossibilidade de dominação de uma das categoriais sociais sobre a outra, mas também como participação no plano político, refletia no movimento imperialista romano ${ }^{17}$.

Assim, como salienta Sasso (1980, p. 476-477), "as leis que se fazem por impulso desses dois "humores", potentes e insuprimíveis, são, sempre, leis de liberdade; e "liberdade" significa aquilo que já sabemos: "força", potência, capacidade de conquistar". Todavia, para ser livre "o estado deve ser forte; para ser livre e forte, deve ser "popular" e “democrático" (SASSO, 1980, p. 475) ${ }^{18}$. E é justamente essa "popularização" do governo, isto é, a prioridade da plebe para a "guarda da liberdade" que, doravante, iremos analisar.

\section{A guarda da liberdade e o aspecto popular: a segunda condição para a potência}

Embora os tumultos romanos tenham sido responsáveis pela concessão da "parte que cabia ao povo na administração [amministrazione]" (Discursos, I, 4, p. 23) da cidade, eles não foram mitigados após a promoção da constituição mista. Ao contrário, as dissensões entre grandes e povo continuaram a manifestar-se no interior da engrenagem republicana. Partindo de um dado agora sólido - a existência incontornável dos dois humores -, Maquiavel se debruça sobre a questão da guarda da liberdade e o motivo pelo qual as instituições romanas a haviam confiado ao povo.

\footnotetext{
${ }^{16}$ De acordo com a intérprete francesa (2004, p. 56), quando nos voltamos para Lívio, identificamos numerosos episódios onde essa barganha era forjada através de tumultos ou da recusa ao alistamento. Por exemplo, diante do ataque dos Sabinos em 457 a.C., a conscrição da plebe é negociada em troca do aumento no número de Tribunos. Do mesmo modo, a possibilidade do casamento entre membros da plebe e membros das famílias patrícias é concedido à plebe por ocasião da guerra contra os Fidênios e os Etruscos, em 445 a.C.

${ }_{17}$ Como afirma Maquiavel "a experiência mostra que as cidades nunca crescem em domínio nem em riquezas, a não ser quando são livres" (Discursos, II, 2, p. 186-187). A relação entre aumento territorial e liberdade se deve ao fato de que aquilo que engrandece as cidades "não é o bem individual, e sim o bem comum. E, sem dúvida, esse bem comum só é observado nas repúblicas, porque tudo o que é feito, é feito para o seu bem" (Discursos, II, 2, p. 187). É lícito pensarmos que o encurtamento da distância entre a grandeza pátria e o interesse individual constitua um importante elemento motivador para o soldado, advindo da plebe, no campo de batalha. O que está em questão, conforme Helton Adverse (2007, p. 38), "é uma identificação entre o bem da cidade e o bem do cidadão".

${ }^{18}$ Com efeito, Sasso opta pelo uso de "democrático" para referir-se ao aspecto da guarda da liberdade depositada sobre as mãos populares. Nessa escolha terminológica, também McCormick direcionará um amplo estudo às atribuições institucionais que o Secretário florentino identificava nas assembleias e tribunatos, através da contestação cívica institucionalizada - o que o norte-americano chama, propriamente, de "democracia maquiaveliana" (cf. MCCORMICK, John P. Machiavellian Democracy. New York: Cambridge University Press, 2011). Contudo, escolhemos por evitar o termo "democracia" por fidelidade textual: em sua obra, Maquiavel não recorre à nomenclatura, ainda que o sentido de "participação popular" esteja latente.
}

ZORZO, Douglas Antônio Fedel. Maquiavel e a função dos tumultos para a potência militar romana. Griot : Revista de Filosofia, Amargosa - BA, v.19, n.2, p.284-299, junho, 2019. 
Ordenar um estado que buscasse a expansão pelas vias militares, como veremos sob a ótica do propósito romano, aparecerá atrelado à essa providência.

Ora, como em "em toda república há homens grandes e populares, não se sabe bem em que mãos é melhor depositar tal guarda" (Discursos, I, 5, p. 24). Diante dessas duas possibilidades, o Secretário florentino realiza uma análise prática de casos - que o orientará no capítulo 5 e ecoará decisivamente no capítulo 6 . Afinal, quais são as funções que cabem à essa instituição? Em quem confiar essa "guarda"? Aos grandes, como haviam feito os espartanos e, em tempos recentes, os venezianos, ou ao povo, como os romanos?

Antes de mais nada, devemos reconhecer que o Secretário florentino deixa uma lacuna sobre o significado institucional específico que atribuía à guardia della libertà. Contudo, como nota Inglese (2015, p. 295, nota 2, tradução nossa), a ela poderíamos remeter um sentido muito semelhante a um poder de "última instância". Isso, por sua vez, superaria a ideia tradicional do governo misto como um simples balanceamento de forças, uma vez que a estabilidade da cidade estaria atrelada à competência de uma daquelas categorias. Na mesma direção, Sasso (2014, p. 441) afirma que a custódia da liberdade é um indicativo de que o ordenamento republicano deveria ser capaz de encontrar, em sua própria estrutura, o princípio e a garantia de sua sobrevivência. Também para o intérprete, a regulação da discórdia, por meio dos mecanismos institucionais - nascidos da própria discórdia! - não implicaria em uma equilibrada distribuição da responsabilidade pela manutenção da República, incorporada nos órgãos fundamentais da arquitetura política da costituzione mista ${ }^{19}$. No pensamento maquiaveliano, insiste, era necessário conferir a uma das partes (exatamente, à popular, como veremos) a tutela e a garantia do todo, pois, assim, o equilíbrio seria melhor realizável do que, ao contrário, caso fosse confiado à moderação formal entre elas.

Enquanto em Roma a observância pela manutenção da liberdade havia sido depositada no povo, Veneza e Esparta a haviam confiado, através de seus processos ordenatórios, à nobreza. Por isso, Maquiavel inicia seu pensamento ponderando os motivos pelos quais cada estado confiou essa atribuição para grupos diametralmente opostos.

\footnotetext{
19 Devemos notar que é justamente nessa direção que Guicciardini, nas Considerazioni sui "Discorsi" del Machiavelli, realiza suas críticas. "Eu não entendo o título da questão, isto é, o que quer dizer o colocar a guarda da liberdade ou no povo ou nos grandes. Porque uma coisa é dizer sobre quem deve estar o governo, ou nos grandes ou na plebe, e para isso serve o exemplo de Veneza, porque é [ordenada] de tal modo sobre os nobres que a plebe é totalmente excluída. Outra coisa é dizer, onde todos participam do governo, a quem deve ser atribuída a autoridade ou o cuidado particular para a defesa da liberdade: ou a um magistrado dos plebeus ou dos nobres, e a isso pode servir o exemplo de Roma, onde, participando os nobres e a plebe, o magistrados dos tribunos parecia que tinha a particular guarda da liberdade (1974, p. 618, tradução nossa)". Porém, "quanto ao título da questão, entre todos os outros [tipos de] governos, eu louvarei mais um governo misto [...], e em um governo similar, eu quererei que a guarda da liberdade, contra quem quisesse oprimir a república, pertença a todos, fugindo sempre que possível da distinção entre nobres e plebeus; e, necessariamente, um governo misto é temperado de modo que, em favor da liberdade, uma ordem é a guarda da outra (1974, p. 619). Como explica Sasso (2014, p. 441), para Guicciardini, um sistema que se constrói sobre a premissa do equilíbrio dos órgãos que o constitui não poderia atribuir a um deles a sua própria garantia. Ao contrário, essa segurança deveria estar situada no próprio equilíbrio dos órgãos, no recíproco controle, não na prevalência de um sobre o outro.
}

ZORZO, Douglas Antônio Fedel. Maquiavel e a função dos tumultos para a potência militar romana. Griot : Revista de Filosofia, Amargosa - BA, v.19, n.2, p.284-299, junho, 2019. 
"E, indo às razões, direi [dico], vendo primeiro o lado dos romanos, que se deve dar a guarda de uma coisa àqueles que têm menos desejo de usurpá-la" ${ }^{20}$. Considerando os objetivos dos nobres e dos plebeus, "veremos naqueles grande desejo de dominar e nestes somente o desejo de não ser dominados e, por conseguinte, maior vontade de viver livres, visto que podem ter menos esperança [meno sperare] de usurpar a liberdade do que os grandes". Sob esse viés, encarregar o povo da guarda da liberdade seria mais prudente, visto que zelam mais por ela, e, "não podendo eles mesmos apoderar-se dela, não permitirão que outros se apoderem". (Discursos, I, 5, p. 24).

Do outro lado estão as razões de "quem defende [chi difende] a ordenação espartana e veneziana", alegando que quem deposita a guarda nas mãos dos poderosos [potenti] realiza com isso duas boas ações [opere buone]: a primeira "é satisfazer mais a ambição deles, que, tendo mais participação na república com tal bastão em mãos, têm mais motivo para contentamento"; a segunda reside no fato que assim "negam certo tipo de autoridade aos ânimos inquietos da plebe, razão de infinitas dissensões e tumultos numa república, capazes de causar alguma reação desesperada à nobreza, o que, com o tempo, produzirá maus efeitos". (Discursos, I, 5, p. 24-25).

O debate, então, se concentra sobre uma dupla alternativa. Qual humor seria mais nocivo à liberdade republicana: aqueles que temem perder algo que já conquistaram, como no caso dos grandes, ou aqueles que pretendem conquistar algo que ainda não possuem, como no caso do povo? A resposta para o dilema dependerá, no final das contas, do propósito que cada estrutura republicana se coloca. Se considerarmos um estado que deseja se expandir, fare uno império, como Roma, a guarda da liberdade deve ser atribuída ao povo. Ao contrário, se as ordenações visarem apenas a manutenção da cidade, a guarda deve ser confiada aos nobres, como Esparta e Veneza haviam feito ${ }^{21}$.

Aparentemente, poderíamos considerar a questão da guarda da liberdade como resolvida, uma vez que o problema sobre "a quem confiá-la?" dependeria de outra premissa, isto é, "qual é o caráter do estado em análise?". Contudo, nesse momento, Maquiavel insiste em nos trazer uma importante colocação. No final, apesar da inclinação expansionista, ou não, de um estado, existe um humor cuja atribuição dessa função revela-se como prejudicial.

De acordo com o Secretário florentino, os "enormes tumultos [tumulti grandissimi]", na maior parte das vezes, são causados por "aqueles que mais possuem, porque o medo de perder gera neles as mesmas vontades que há nos que desejam conquistar". Com efeito, "os homens só acham que possuem com segurança o que têm quando acabam de conquistá-lo de outro" (Discursos, I, 5, p. 26). Em outras palavras, o temor de perder o que se possui impele os homens a cometerem as

\footnotetext{
20 Segundo Claude Lefort (1972, p. 477, tradução nossa) não podemos desconsiderar o fato de que quando Maquiavel escolhe o exemplo romano fala em "seu próprio nome, fazendo preceder o argumento de um "eu digo" (dico), enquanto que põe na boca de um interlocutor indeterminado a defesa de Esparta e de Veneza (chi defende l'ordine spartano o veneto dice)".

21 "E no fim, quem examinar tudo sutilmente chegará a esta conclusão: ou se pensa numa república que queira fazer um império, como Roma, ou numa à qual baste manter-se. No primeiro caso, é necessário fazer tudo como Roma; no segundo, pode-se imitar Veneza e Esparta". (Discursos, I, 5, p. 25)
} 
mesmas violências daqueles que desejam adquirir. Não existe, portanto, a possibilidade de uma pura conservação, pois conservar é querer sempre mais.

Para Lefort (1972, p. 478), o argumento de inspiração aristocrata acaba anulado, uma vez que é revelado que "repousava sobre uma mentira": desejo dos grandes "não é o de conservar o adquirido, o qual é insaciável, que é desejo mesmo de adquirir". Por esse ângulo, o equívoco de que os nobres seriam os verdadeiros responsáveis pela paz civil, dado seu apetite pela simples conservação, é descoberto. Isto é, também os grandes promovem seus tumultos.

Mas, a questão é ainda mais profunda. Nos desdobramentos de seus acontecimentos, a "conflitualidade" romana, chancelada pela atribuição da salvaguarda da liberdade ao povo, era uma das condições para servir-se dessa força nos campos de batalha. Incumbir a mesma atribuição aos nobres era um capricho que somente os estados preocupados em manter-se dentro de seus limites exíguos portanto, sem a necessidade de armar-se e conceder autoridade política ao povo podiam desfrutar. Atribuição frágil, uma vez que a pouco descobrimos que na raiz do desejo dos grandes encontra-se o ímpeto de voltar-se contra o povo sempre que possível, e, com isso, ameaçar sua liberdade. De todos os modos, conflitos internos, tranquilidade social e expansão, aqui, se interconectam. E é justamente para abordar os termos dessa relação que Maquiavel entra, no capítulo 6, na comparação entre as repúblicas conservacionistas e expansionistas.

\section{Entre modelos de república e o domínio da Fortuna: conservar-se ou expandir-se?}

Seguindo a trama dos conflitos, o Secretário florentino lança uma importante questão: afinal, poderia Roma ter chegado à tamanha grandeza (política, territorial e, assim, histórica) caso tivesse eliminado as inimizades entre o povo e os grandes? Para conjecturar sobre isso, afirma, é necessário "recorrer às repúblicas que sem tantas inimizades e tumultos permaneceram livres por longo tempo, vendo que tipo de estado nelas havia, e se era possível introduzi-lo em Roma" (Discursos, I, 6, p. 27). Para compor esse quadro comparativo, serve-se do nome de duas repúblicas que pairam sobre o imaginário político florentino: Esparta, como um exemplo antigo, e, em especial, Veneza, como moderno. A partir disso, o Secretário florentino reconstrói, pelas vias históricas ${ }^{22}$, os motivos pelos quais essas duas cidades foram capazes de promover o apaziguamento dos conflitos internos - coisa que estruturas romanas não tiveram a capacidade, ou a pretensão, de fazer.

As ordenações venezianas ${ }^{23}$, responsáveis por uma constituição que resguardava-se dos tumultos, surgiram sob a sombra do acaso $[\text { caso }]^{24}$. Reunidos

\footnotetext{
${ }^{22}$ Maquiavel realiza esse movimento de reconstrução porque se dá conta de que não poderia comparar repúblicas historicamente diferentes como se fossem iguais. Para Sasso (1980, p. 481), nesse momento era essencial o "estudo da sua gênese, da sua composição social, dos seus escopos", para, só então, analisar se este modelo era cabível às ordenações romanas. Com grande equilíbrio, banindo "todo apriorismo doutrinário", o autor coloca "rigorosos termos históricos o problema de Esparta, Roma, Veneza e de seu confronto". Não discute, ao menos nesse primeiro momento, a "superioridade de uma sobre a outra", mas "estuda sua gênese" e a "sua fisionomia específica" (SASSO, 1980, p. 483).

${ }^{23} \mathrm{Na}$ História de Florença, Maquiavel condensa a biografia de Veneza no capítulo 29 do Livro I. "Quando Átila, rei dos hunos, sitiou Aquiléia, seus habitantes [...] perderam a esperança de salvar-se e [...] saíram com o que conseguiram carregar e refugiaram-se nos muitos escolhos desabitados que havia na ponta do mar Adriático. Os paduanos também, vendo que o incêndio estava próximo [...] levaram tudo que podiam carregar de mais valor
}

ZORZO, Douglas Antônio Fedel. Maquiavel e a função dos tumultos para a potência militar romana. Griot : Revista de Filosofia, Amargosa - BA, v.19, n.2, p.284-299, junho, 2019. 
sobre os escolhos, o crescimento no número de habitantes exigia, para que pudessem viver juntos, leis, ordenando, assim, uma forma de governo. Organizando-se em conselhos, para "deliberar sobre a cidade", quando "lhes pareceu ser seu número suficiente para constituírem uma vida política, vedaram a todos os que ali passassem a morar o acesso à participação em seu governo". Com o tempo, muitos habitantes ficaram de fora dessa participação no governo. Assim, com o intuito de dar reputação aos que governavam, nomearam estes "gentis-homens", e, aqueles, "populares". Como consequência, Veneza pôde nascer e permanecer incólume aos conflitos, pois, em seu surgimento, "todos os que ali moravam então participaram do governo"; e os "que lá foram morar depois, encontrando o estado fixado e delimitado, não tinham razão nem facilidade para criar tumulto" (Discursos, I, 6, p. 27-28). Nesse caso, pondera, não havia razão para tumulto porque nada havia sido retirado desses habitantes cuja participação no governo era limitada, tampouco havia facilidade para isso, uma vez que quem governava "os mantinha refreados e não os empregava em coisas das quais eles pudessem extrair autoridade" (Discursos, I, 6, p. 28), como na guerra.

Esparta, por outro lado, governada por um rei e por um senado stretto, ordenações instauradas por Licurgo no contexto da fundação, foi capaz de conservarse por "longo tempo", porque nela haviam poucos habitantes e a permissão para a entrada de forasteiros era vedada. Por isso, não tiveram "ocasião para corromperse", diante de outros costumes, nem "para crescer tanto" ao ponto de o governo tornar-se insuportável àqueles que a governavam (Discursos, I, 6, p. 29). Na verdade, os lacedemônios mantinham a unidade interna simplesmente por acatarem as "leis de Licurgo com reverência", cuja "observância eliminava todas as razões para tumultos". A tranquilidade social era assegurada pelo fato de que as leis instituídas pelo ordenador haviam criado "mais igualdade de bens [equalità di sustanze] e menos igualdade de cargos [equalità di grado]", uma vez que havia "igual pobreza, e os plebeus não eram ambiciosos" dado que os "cargos da cidade se distribuíam por poucos cidadãos e eram mantidos fora do alcance da plebe, enquanto os nobres nunca lhe deram, com maus-tratos, desejo de possuí-los" (Discursos, I, 6, p. 28-29).

Ou seja, a Serenissima Repubblica di Venezia ${ }^{25}$ foi capaz de preservar a harmonia em seu interior, em primeiro lugar, por condições ambientais particulares;

para o mesmo mar, a um lugar chamado Rivo alto [...]. Além disso, os habitantes de Monselice e das colinas dos
arredores, movidos pelo mesmo terror, foram para os escolhos do mesmo mar [...]. Do mesmo modo, todos os
povos vizinhos daquela região que antigamente se chamava Venécia, impelidos pelos mesmos acontecimentos,
foram para aqueles charcos. Assim, compelidos pela necessidade, deixaram lugares amenos e férteis para morar
em lugares estéreis, repugnantes e isentos de toda comodidade. E, como muitos povos ali se reuniram ao mesmo
tempo, logo aqueles lugares se tornaram não só habitáveis, mas também agradáveis; e, estabelecendo leis e
ordenações, em meio às ruínas da Itália gozavam de segurança [...]. E, enquanto os venezianos viveram dessa
forma, seu nome foi temível nos mares e venerável na Itália [...]. Mas, com o tempo, depois que ocuparam Pádua,
Vicenza e Treviso, bem como Verona, Bérgamo e Brescia, além de muitas cidades do Reino [de Nápoles] e da
Romanha, impelidos pela cupidez de dominar, passaram a ser considerados tão poderosos que infundiram terror
não só nos príncipes italianos, mas também nos reis ultramontanos; por isso, aliando-se todos contra eles, em um
dia lhes foi arrebatado todo aquele estado que em muitos anos, com infinitos custos, haviam conquistado" (p. 58-
60 ).
24 "Esse modo lhes foi ditado mais pelo acaso que pela prudência de quem lhes deu as leis" (Discursos, I, 6, p. 27).
25 Devemos lembrar que o mito de Veneza povoava o imaginário dos republicanos florentinos desde o tempo de
Savonarola, tendo servido, inclusive, de modelo para algumas reformas políticas em Florença. Sobre a influência

ZORZO, Douglas Antônio Fedel. Maquiavel e a função dos tumultos para a potência militar romana. Griot : Revista de Filosofia, Amargosa - BA, v.19, n.2, p.284-299, junho, 2019. 
depois, tendo sido a nobreza constituída por todos os seus primeiros habitantes, incluídos no governo da república, os tumultos não encontraram espaço nem razões para atribularem sua história. Enquanto isso, Esparta ${ }^{26}$ garantiu a homonóia ao assegurar a "igualdade das fortunas" e ao impedir a entrada de estrangeiros, motivo que evitou a corrupção das leis de Licurgo, o que a permitiu "se manter igual a si mesma por muitos séculos" (BIGNOTTO, 2005, p. 92).

Diante dessas ordenações, que foram capazes de mitigar os conflitos, poderia Roma ter alcançado a mesma grandeza caso tivesse sido politicamente disposta como Esparta ou Veneza? A resposta de Maquiavel é lacônica - contrariado, especialmente, os republicanos florentinos de tendência filoaristocrata -: "se Roma quisesse eliminar as razões dos tumultos, eliminaria também as razões de ampliar-se" (Discursos, I, 6, p. 29). A supressão dos conflitos internos e a tranquilidade, aos moldes das supracitadas cidades, implicava que a República ou não tivesse empregado a "plebe na guerra", como haviam feito os venezianos, ou que não tivesse aberto "caminho para os forasteiros", como os espartanos. Mas "fizeram ambas as coisas, o que deu à plebe força $[\text { forze }]^{27}$, número e infinitas ocasiões para criar tumultos". Ou seja, se o "estado romano se tornasse mais tranquilo [quiete], decorreria o inconveniente de tornar-se também mais fraco [debile], porque assim lhe era barrado o caminho para chegar a grandeza a que chegou" (Discursos, I, 6, p. 29).

Ora, se o estado quieto está diretamente relacionado à debolezza - pensada, propriamente, em termos militares -, então, a conexão entre a desunião da Plebe e do Senado e a potência romana torna-se mais perceptível. Como Esparta e Veneza não se voltaram à formação de um império, bastando a manutenção da própria liberdade, não foi necessário que o povo fosse armado, e, com isso, a ele fosse concedido autoridade política: assim, puderam gozar da calmaria interna e da estabilidade do corpo político. Roma, ao decidir pelo império, como nota John G. A. Pocock (1975, p. 198, tradução nossa), precisou "armar o povo, padecer dos conflitos causados por suas exigências por mais poder, e fazer concessões àquelas demandas".

Diante desse cenário, Maquiavel reintroduz uma distinção já antes relevante. No final, devemos avaliar se estamos lidando com um estado conservacionista ou expansionista. Seu foco está, a partir de agora, em balizar como a existência interna de tumultos e dissensões refletem na política externa. Assim, se "alguém [...] quiser ordenar uma nova república, terá de examinar se quer que ela cresça em domínio e poder, como Roma, ou que permaneça dentro de limites exíguos", como Veneza e Esparta (Discursos, I, 6, p. 30).

\footnotetext{
do mito de Veneza em Florença ef. GILBERT, Felix. La costituzione veneziana nel pensiero politico florentino. In: GILBERT, Felix. Machiavelli e il suo tempo. Bologna: Il Mulino, 1977. p. 115-167. Cf. também GAILLENIKODIMOV, Marie. L'ideale del governo misto tra Venezia e Firenze: un aristotelismo politico a doppia faccia. Filosofia Politica, XIX, $\mathbf{n}^{\circ}$ 1, p. 63-76, 2005. Sobre Maquiavel e Veneza cf. GILBERT, F. Machiavelli e Veneza. GILBERT, Felix. Machiavelli e il suo tempo. Bologna: Il Mulino, 1977. p. 319-334. SASSO, Gennaro. Machiavelli e Venezia. Considerazioni e appunti. In: SASSO, Gennaro. Machiavelli e gli antichi e altri saggi. Vol. III. Milano/Napoli: Riccardo Ricciardi Editore, 1988. p. 3-46.

${ }^{26}$ Sobre Maquiavel e Esparta, cf. CADONI, Giorgio. Machiavelli e i tardi riformatori di Sparta. In: CADONI, Giorgio. Crisi della mediazione politica e conflitti sociali: Niccolò Machiavelli, Francesco Guicciardini e Donato Giannotti di fronte al tramonto della Florentina libertas. Roma: Jouvence, 1994. p. 47-91.

${ }^{27}$ Para Inglese (2015, p. 209, nota 18), a "força" cumpre um sentido específico: graças ao exercício das armas, o povo se torna forte. Ao contrário, deixados desarmados, se tornam "vis", incapazes de defender a si próprios e à república.
}

ZORZO, Douglas Antônio Fedel. Maquiavel e a função dos tumultos para a potência militar romana. Griot : Revista de Filosofia, Amargosa - BA, v.19, n.2, p.284-299, junho, 2019. 
Os ordenadores que desejam que a república se expanda, devem buscar inspiração no modelo romano, e "dar lugar da melhor maneira possível a tumultos e a dissensões entre cidadãos", pois "sem grande número de homens bem armados, nunca república alguma poderá ampliar-se, e, caso se amplie, não poderá manter-se" (Discursos, I, 6, p.30). Isso decorre do fato de que "se queres [tu vuoi] criar um povo numeroso e armado para poderes criar um grande império, acabarás por fazê-lo de tal maneira que não poderás depois manejá-lo [maneggiare] a teu modo" (Discursos, I, 6, p. 30). Deverá, assim, procurar a institucionalização dos conflitos e o sfogo aos humores.

Para ordenar uma república à qual baste se manter, como Esparta e Veneza, será necessário manter o povo "pequeno" ou "desarmado", para "poderes manejálo", e, com isso, evitar os tumultos e garantir um estado harmonioso. Porém, o ordenador com esse propósito deve ter o cuidado de que as leis e ordenações ali instituídas evitem, sob todas as hipóteses, que a cidade se lance em expedientes de conquistas, visto que "o crescimento é o veneno de semelhantes repúblicas" (Discursos, I, 6, p. 30). Essas conquistas, "se apoiadas numa república fraca [debole]", militarmente desestruturada, "são motivo de sua ruína" (Discursos, I, 6, p. $31)$.

Contudo, alerta Maquiavel, evitar que um estado cresça territorialmente independe dos propósitos de um ordenador ou de ordenações. A realidade é variada, pondera Sasso (1980, p. 483), e precisa ser adequada periodicamente, não admitindo medidas unívocas de avaliação. Repúblicas como Esparta e Veneza, determinadas a permanecer em breves termos, estão, na realidade, constantemente expostas às variações da fortuna. Para Pocock (1975, p. 198-199), caso a cidade conseguisse evitar o contato com seus vizinhos, poderia "limitar seus exércitos e viver para sempre em uma estabilidade aristocrática". Mas, como "isso não pode ser feito, rejeitar a expansão é se expor à fortuna sem procurar dominá-la" 28 .

O problema de ordenar uma cidade que não reconheça o povo como sujeito político encontra, enfim, o seu desfecho. A carência de um povo armado, derivada da assunção da aristocracia como guarda da liberdade e da pretensão de manter a concórdia interna, expõe a fragilidade dessas ordenações caso se voltem ao campo militar: caso "conquistares domínios, não os poderás conservar ou eles se tornarão tão fracos que serás presa fácil de quem te atacar" (Discursos, I, 6, p. 30).

Foi o que ocorreu com Esparta e Veneza, que operam como prova de que quando tais cidades são impelidas pela necessidade a abandonar o modelo conservacionista, acabam se arruinando. Com o intuito de defender sua liberdade, foram obrigadas a impor-se aos territórios circunvizinhos, empreendimento malsucedido tanto para a elite militar de Esparta quanto para os mercenários contratados por Veneza. A primeira, após submeter "quase toda a Grécia", mostrou "num mínimo acontecimento como era fraco o seu fundamento [debile fondamento suo], porque, em seguida à rebelião de Tebas, provocada por Pelópidas, veio a

\footnotetext{
${ }^{28}$ Como propõe Lefort (1972, p.481), é vão “erigir a segurança em princípio de ação, pois os efeitos do tempo não poderiam ser dominados por ninguém". Além disso, a necessidade conduz onde a razão não quer ir, ou seja, o estado cresce "apesar da decisão daqueles que pretendiam fixar-lhe seu limite ou então se, por sorte, se subtrai por muito tempo aos perigos, as virtudes do povo enfraquecem e seu cálculo é frustrado".
} 
rebelião das outras cidades, que arruinou de todo aquela república"29. A segunda, “depois de ter ocupado grande parte da Itália - e a maior parte não com guerra, mas com dinheiro e astúcia -, quando precisou dar provas de suas forças, perdeu tudo em uma só batalha" (Discursos, I, 6, p. 31), a saber, na de Agnadello, contra a liga de Cambrai, formada para conter o expansionismo veneziano.

Portanto, ambas as cidades, quando impelidas pela necessidade a abandonar o modelo de conservação, tiveram seus fundamentos destruídos. Isto é, uma república daquele modo ordenada, quando forçada a ampliar, acaba invariavelmente sendo conduzida à ruína. Por outro lado, conjectura hipoteticamente Maquiavel, "sempre que o Céu lhe fosse tão benévolo que não lhe cumprisse guerrear, o ócio a tornaria [a cidade] efeminada ou dividida; coisas que, juntas ou cada uma por si, seriam razão para sua ruína" (Discursos, I, 6, p. 32) ${ }^{30}$. Dessa forma, a potência parece ser a única chave de sobrevivência. Ou melhor, as repúblicas não podem sobreviver, a não ser ampliando continuamente seus domínios (cf. AMES, 2009, p.189-190), para que não sejam vítimas da guerra ou do ócio.

Assim, dentre as formas institucionais analisadas pelo Secretário florentino, aquela romana se revela como a mais competente para lidar e dominar as eventualidades da fortuna - diferente das constituições espartanas e venezianas, que, retraídas na aspiração de concórdia, permaneciam à mercê de seus desígnios. Toda a argumentação maquiaveliana acaba direcionada à consolidação da pertinência do regime popular. "Creio", afirma, "ser necessário seguir a ordenação romana e não a das outras repúblicas", pois "não acredito ser possível encontrar um meio termo entre uma e outra, e as inimizades que surgissem entre o povo e o senado deveriam ser toleradas e consideradas um inconveniente necessário para se chegar à grandeza romana" (Discursos, I, 6, p.32). No horizonte, o ordenamento político romano surge como paradigma constitucional, justamente pela melhor preparação contra as eventualidades da fortuna. No contexto de uma ampliação forçada, impelida pelo signo da necessidade, a cidade deveria estar apta para que pudesse levá-la a efeito. Logo, deveria estar institucionalmente dotada de uma estrutura de amparo político à categoria popular, para, com isso, "voltar-se para onde lhe ordenarem os ventos da fortuna e as variações das coisas" (O Príncipe, XVIII, p.85).

\section{Considerações finais}

Assim, com esse percurso, podemos afirmar que os tumultos entre os nobres e a plebe possibilitaram que o povo tomasse parte nos assuntos políticos da República de Roma. Como consequência desse reconhecimento institucional, o "povo em armas" operou não apenas em meros soldados, mas como um exército em condições de conquistar o "mundo" e assegurar com firmeza os interesses daquele estado -

\footnotetext{
${ }^{29}$ De acordo com Inglese (2015, p. 210, nota 27), Tebas rebelou-se contra a supremacia dos lacedemônios em 379 a.C.. Oito anos depois, os tebanos, sob o comando de Pelópidas, derrotaram os espartanos em Leuctra, provocando o fim de sua hegemonia.

30 No capítulo 1 do Livro 5 da História de Florença encontramos a dimensão desordenadora causada pelo ócio nesse contexto: a virtù "gera a tranquilidade, a tranquilidade gera o ócio; o ócio a desordem, e a desordem a ruína" (p. 281).
} 
destreza à qual Maquiavel estenderá o status de paradigma para as ordenações militares romanas ${ }^{31}$.

Conforme buscamos argumentar, conceder ao povo seu papel ativo no regime republicano significava, para Maquiavel, o máximo controle possível das investidas da fortuna. Ao contrário das repúblicas conservacionistas e aristocratas, que também testemunhavam a cisão do tecido social em dois humores, Roma não buscou sufocar os conflitos em nome de uma pretensa harmonia. Aquelas repúblicas foram obrigadas a desestabilizarem o equilíbrio interno a partir dos eventos que impactavam a ordem externa. Negar o papel político do povo - neutralizando, com isso, os riscos e os inconvenientes que os tumultos portavam consigo - foi a causa do encaminhamento das estruturas republicanas aristocráticas ao caos militar externo.

Dito de outra maneira, a possibilidade de existência dos tumultos internos é a responsável por assegurar a eficácia diante dos conflitos externos. Isto é, regular institucionalmente os eventos que atribulam a ordem política interna é dar garantias para que os eventuais confrontos externos, de certa maneira inevitáveis e alheios à vontade do estado, sejam exitosos. Por essa razão, a liberdade externa se revela como complemento à manutenção da liberdade interna: os indivíduos, grandes e povo, só podem gozar da liberdade que lhes é peculiar (o desejo de dominar ou o desejo de não ser dominado) caso a liberdade do próprio estado seja assegurada. Do mesmo modo, a liberdade externa é afiançada pela expressão institucional dos humores. E é nisso que Roma encontra o fundamento de sua grandeza e deixa como legado à História política.

31 As ordenações militares da República de Roma figuram em Maquiavel como o modelo justo a ser imitado nas ordenações modernas de infantaria e cavalaria. A exemplaridade desses modos, e os meios para transpô-los aos tempos modernos, são apresentados por Maquiavel n'A Arte da Guerra (Cf. MAQUIAVEL, Nicolau. A Arte da Guerra. Tradução de MF. São Paulo: Martins Fontes, 2006). Sobre as maneiras como os romanos se portavam nos campos de batalha, aspectos técnicos e comportamentais cf. o livro II dos Discursos sobre a primeira década de Tito Livio. Tradução de MF. São Paulo: Martins Fontes, 2007. p. 177-303. 


\section{Referências:}

ADVERSE, Helton. Maquiavel, a república e o desejo de liberdade. Trans/Form/Ação, v.30, n.02, p.33-52, 2007.

AMES, José Luiz. Liberdade e conflito: o confronto dos desejos como fundamento da ideia de liberdade em Maquiavel. Kriterion, n.119, p.179-196, 2009.

BIGNOTTO, Newton. Maquiavel republicano. $2^{\text {a }}$ ed. São Paulo: Edições Loyola, 2005.

GAILLE-NIKODIMOV, Marie. Conflit civil et liberté: La politique machiavélienne entre histoire et médiecine. Paris: Honoré Champion, 2004.

GEUNA, Marco. Machiavelli ed il ruolo dei conflitti nella vita politica. In: ARIENZO, Alessandro; CARUSO, Dario (org.). Conflitti. Napoli: Libreria Dante \& Descartes, 2005. p.19-57.

GUICCIARDINI, Francesco. Opere I. A cura di Emanuella Lugnani Scarano. Torino: UTET, 1974.

INGLESE, Giorgio. Premessa al testo e note. In: MACHIAVELLI, Niccolò. Discorsi sopra la prima deca di Tito Livio. $10^{\text {a }}$ ed. A cura di Giorgio Inglese. Milano: BUR Classici, 2015.

LEFORT, Claude. Le travail de l'oeuvre Machiavel. Paris: Gallimard, 1972.

MACHIAVELLI, Niccolò. Discorsi sopra la prima deca di Tito Livio. $10^{\mathrm{a}}$ ed. A cura di Giorgio Inglese. Milano: BUR Classici, 2015.

MACHIAVELLI, Niccolò. Opere. A cura di Corrado Vivanti. Torino: EinaudiGallimard, 1997.

MAQUIAVEL, Nicolau. Discursos sobre a primeira década de Tito Lívio. Trad. de MF. São Paulo: Martins Fontes, 2007.

MAQUIAVEL, Nicolau. História de Florença. Trad. de MF. São Paulo: Martins Fontes, 2007.

MAQUIAVEL, Nicolau. O Príncipe. 2aa ed. Trad. de Maria Júlia Goldwasser. São Paulo: Martins Fontes, 1998.

MCCORMICK, John. Machiavellian Democracy: Controlling Elites with Ferocious Populism. American Political Science Review, v.95, n.2, p.297-313, 2001.

POCOCK, J. G. A. The Machiavellian moment: Florentine Political thought and the Atlantic Republican Tradition. Princeton: Princeton University Press, 1975.

SASSO, Gennaro. Discorsi sopra la prima deca di Tito Livio. In: SASSO, Gennaro (org.). Machiavelli: Enciclopedia Machiavelliana. Vol. I. Roma: Istituto della Enciclopedia Italiana fondata da Giovanni Treccani, 2014. p.427-458.

SASSO, Gennaro. Niccolò Machiavelli: storia del suo pensiero politico. Bologna: Il Mulino, 1980.

SFEZ, Gérald. Machiavel, la politique du moindre mal. Paris: Presses Universitaires de France, 1999.

Autor(a) para correspondência: Douglas Antônio Fedel Zorzo, Universidade do Estado do Paraná, Rua da Faculdade, $\mathbf{n}^{\circ}$ 645, Jardim La Salle, 85903-000, Toledo - PR, Brasil. douglasfedel@hotmail.com 